IZA DP No. 4881

Neighbourhood Child Poverty in Sweden

Bjorn Gustafsson

Torun Österberg

April 2010 


\title{
Neighbourhood Child Poverty in Sweden
}

\author{
Bjorn Gustafsson \\ University of Gothenburg \\ and IZA \\ Torun Österberg \\ University of Gothenburg
}

\section{Discussion Paper No. 4881 \\ April 2010}

IZA

P.O. Box 7240

53072 Bonn

Germany

Phone: +49-228-3894-0

Fax: +49-228-3894-180

E-mail: iza@iza.org

Any opinions expressed here are those of the author(s) and not those of IZA. Research published in this series may include views on policy, but the institute itself takes no institutional policy positions.

The Institute for the Study of Labor (IZA) in Bonn is a local and virtual international research center and a place of communication between science, politics and business. IZA is an independent nonprofit organization supported by Deutsche Post Foundation. The center is associated with the University of Bonn and offers a stimulating research environment through its international network, workshops and conferences, data service, project support, research visits and doctoral program. IZA engages in (i) original and internationally competitive research in all fields of labor economics, (ii) development of policy concepts, and (iii) dissemination of research results and concepts to the interested public.

IZA Discussion Papers often represent preliminary work and are circulated to encourage discussion. Citation of such a paper should account for its provisional character. A revised version may be available directly from the author. 
IZA Discussion Paper No. 4881

April 2010

\section{ABSTRACT}

\section{Neighbourhood Child Poverty in Sweden}

This paper takes a fresh look at child poverty at the neighbourhood level in the three metropolitan regions of Sweden using unique data for 1990, 1996 and 2002. We find that the number of neighbourhoods with high child poverty rates is much larger in 2002 than in 1990, but also that most poor children in the three regions live outside poor neighbourhoods. A disproportionally large fraction of children with backgrounds from low- and middle-income countries live in poor neighbourhoods. Regression analysis shows that high neighbourhood poverty rates are mainly due to parents' low employment and to low parental education.

JEL Classification: $\quad$ I32, J13, R23

Keywords: child poverty, neighbourhood, Sweden

Corresponding author:

Björn Gustafsson

Department of Social Work

University of Gothenburg

P.O. Box 720

SE 40530 Göteborg

Sweden

Email: Bjorn.Gustafsson@socwork.gu.se

\footnotetext{
* Revised version of paper prepared at the FISS Seminar on Social Security, Poverty and Social Exclusion in Rich and Poor Countries, Sigtuna, Sweden on 16-18 June 2009. It develops material presented and discussed at the $30^{\text {th }}$ General Conference of the International Association for Research in Income and Wealth, Portoroz, Slovenia, August 24-30, 2008. We thank Markus Jäntti for comments on that version.
} 


\section{Introduction}

The issue of residential segregation and child poverty has been added to the political agendas of many rich European countries. One important reason for this is that a high proportion of immigrants from low- and middle-income countries have not been successful in finding fulltime jobs. Without wage income or being entitled to social security transfers, a disproportional fraction of immigrants and their children are at poverty risk. Low spending power causes many immigrants and their dependent children to reside in less-privileged neighbourhoods of larger cities. Such a spatial concentration is often seen as an obstacle in the integration process into the host country. For children, residential segregation means a risk of low human capital development and of acquiring preferences different from those held by the majority. Residential segregation, particularly that having an ethnic aspect, can foster social tension and unrest. The situation in France in the autumn of 2005 provides an alarming example.

In this paper we will provide new results on the extent of urban child poverty at the neighbourhood level in Sweden. True, in international comparisons Sweden typically stands out as a country with little child poverty (see for example OECD, 2008 p 138). Sweden is also well-known for its ambitious social programs and equal distribution of income. This paper confirms that child poverty rates are low in an overwhelming fraction of all neighbourhoods in the three metropolitan regions of Sweden. However, it also shows that from a low base, the number of poor neighbourhoods and children living in them has increased during the period studied here, that is from 1990 to 2002. Such a development has not passed policy makers unnoticed, and for the first time ever, a metropolitan policy for Sweden was formalised in 1998 (Ministry of Finance, 1998). This policy consists of programs aiming at supporting disadvantaged areas (Andersson, 2006).

This paper takes up where Biterman, Gustafsson and Österberg (2008) left off in their analysis of inequality in child income across neighbourhoods in Sweden's three metropolitan areas 1990, 1996 and 2002. Using a new definition of neighbourhood and register data, the study showed that larger and larger proportions of inequality in child income could be attributed to differences in mean income across neighbourhoods. Thus residential segregation, measured in this way, was shown to have increased. The study also concluded, based on estimated regression models, that increased returns to parental characteristics forcefully contributed to 
larger economic polarisation among children in Sweden's metropolitan areas. Changes in the income generating process, not in parental characteristics, were found to be the driving force.

In this paper we carry the analysis of residential segregation in Sweden's three metropolitan areas forward along two different lines. First, we report on child poverty rates and their changes for more than 500 neighbourhoods. When doing this we investigate how child poverty varies by ethnic composition of the neighbourhood. We also study the link between parental characteristics and neighbourhood child poverty rates.

Turning to results we show that the development towards larger polarisation across neighbourhoods also shows up in child poverty rates. The numbers of neighbourhoods with child poverty rates lower than 10 percent as well as the number of neighbourhoods with child poverty rates of at least 40 percent were larger in 2002 than in 1990. However, though there is a clear tendency for child poverty to become more spatially concentrated, in 2002 most poor children in metropolitan areas still actually live outside poor neighbourhoods. There is a very strong relation between ethnic composition and child poverty rate at the neighbourhood level. Neighbourhoods with high fractions of visible minorities have increasingly higher child poverty rates than neighbourhoods dominated by the majority population. We find than a rather high proportion of the variation in child poverty rates across neighbourhoods can be explained by a small number of variables measuring parental characteristics at the neighbourhood level. Most importantly, low parental employment and low parental education predict high neighbourhood child poverty rates while foreign origin has little independent influence.

The rest of the paper is laid out as follows: In the following section we discuss central concepts for this study and their measurement. Section 3 reports on child poverty rates by neighbourhoods for the three years 1990, 1996 and 2002. The relation between poverty and ethnicity of the neighbourhood is investigated in Section 4. Finally, we sum up the conclusions in Section 6. 


\section{The concepts of neighbourhood and child poverty}

In this study, a neighbourhood is defined as an area smaller than a municipality, but larger than a city block; as such it represents a convenient intermediate level. Since the neighbourhood represents a natural social arena for its residents, it is an understandable choice of sub-arena. Furthermore, our division into neighbourhoods is not dependent on administrative changes, which means that the borders do not change during the period under review. $^{2}$

The neighbourhood is defined as a populated area that:

- $\quad$ is demarcated by natural borders (larger streets, green areas, etc).

- $\quad$ corresponds to a city district or a residential area.

- $\quad$ possesses a number of inhabitants large enough to provide the basis for certain private or public services (most often between 4000 and 10000 inhabitants).

- $\quad$ is identified as a neighbourhood by its inhabitants.

In accordance with these criteria, such a geographic divisions into neighbourhoods have been established for the three metropolitan regions of Sweden, i.e., the municipalities of Stockholm, Gothenburg and Malmö, see Table 1. Of Sweden's 9 million inhabitants, 3.3 million or 37 percent live in the three metropolitan regions. The region around Stockholm, the capital, in the mid-eastern part of the country is the largest, and consists of not less than 24 municipalities (city level units). Eight municipalities make up the Gothenburg region on the west coast, which is the second largest region by population. As is usually the case for these types of studies, we treat Malmö in the south and the eight municipalities surrounding it as a separate region, although if the national border to Denmark is disregarded, the Malmö region can be considered to be the eastern (and smaller) part of the Copenhagen-Malmö region. After deleting some neighbourhoods with few children, we are left with information on 574 neighbourhoods which form the subject of the analysis.

/Table 1 about here/

\footnotetext{
${ }^{2}$ The classification is further presented in Biterman and Franzén (2007).
} 
Table 1 shows that the foreign-born population ranges from 15 percent in the Gothenburg region to 18 percent in the Stockholm region. Finland is the largest sender country of foreign born living in the Stockholm region and ranks number two among sender countries to the Gothenburg region, but much lower in the Malmö region. In contrast Poland is the second largest country of foreign born living in the Malmö region, but ranks much lower in the other two regions. If Yugoslavia and its successor states are considered to be one entity, it is the single largest sender country for the Gothenburg and Malmö regions. Other high rank sender countries are Iraq, Iran and Turkey. In the Swedish context, various forms of discrimination and social exclusion are perceived as social problems for some, but not all, foreign born. For reasons discussed in Section 4 we will therefore distinguish between visible immigrants and other immigrants and the ethnic classification introduced and used in that section is based on the fraction visible immigrants.

We define a child as a person under age 18 and measure his or her economic situation based on the disposable income of the parents. An important component of a household's disposable income is wages subject to income tax. In addition, there can be income from capital received as dividends and interest as well as income from capital gains from selling stocks and property. Disposable income also includes public transfers such as pensions, sickness benefits, child allowances and social assistance. After adding the various income components we subtract income taxes paid and arrive at disposable income at the household level.

In order to make comparisons across households with different numbers of members we adjust the disposable income of each household with its equivalent scale number, using an equivalence scale often used by Statistics Sweden. ${ }^{3}$ Finally, each person is assigned this income. Persons having an equivalent disposable income of less than 60 percent of the median (computed for all individuals in Sweden; children as well as adults) as observed the same year are classified as poor or non-poor. Child poverty rates for a neighbourhood refer to the proportion of children (persons under 18 years of age) deemed to be poor in relation to the total number of children in the same neighbourhood. In some of the analyses we will also investigate proportion of children that fall under a poverty line set at 40 percent of the contemporary median, thus mapping deep poverty.

\footnotetext{
${ }^{3}$ This equivalence scale, recommended by the National Board of Health and Welfare, starts with 1.16 for the first adult in the household, assigns the value 1.92 for two adults and adds weights of 0.56, 0.66 and 0.76 for each child aged 0-3 years, 4-10 years and 11-17 years respectively.
} 
Among various definitions of poverty, the definition chosen here has two advantages. It is widely used when assessing poverty among member states of the European Union as for example Eurostat publishes measures of poverty in the member states based on it, see also Atkinson et al (2002). Please note that our poverty line is defined based on median income for all inhabitants (independent of age) in Sweden (not only the three metropolitan areas).

The information for deriving disposable income comes from Statistics Sweden which in turn has compiled information from tax files as well as from registers on public transfers received. We work with data on all children in the three metropolitan regions in Sweden, not a sample. While this is a desirable property, there are measurement problems that might affect our results. One problem is that we work with a narrowly defined income-pooling and need unit as this is defined as married couples or cohabiting adults with a common child and their dependent children (persons under 18 year of age). We cannot know if the real income sharing unit also includes other persons over 18 years of age. ${ }^{4}$ The narrow definition of the household is not shared by the Household Income Survey conducted annually by Statistics Sweden. The Household Income Survey, which has been available in the Luxembourg Income Study (LIS) for some years, provides a better basis for estimating child poverty in Sweden as a whole. However, being a sample survey it cannot be broken down at the neighbourhood level. As in similar studies, incomes that are not noted in the registers are not known to us, and cannot affect the classification of a household as poor or not.

The analysis covers each of the years 1990, 1996 and 2002, thus making it possible to investigate changes over time. Between the first pairs of years the Swedish economy went into a deep recession, unemployment increased, labour force participation fell and median income changed only little. In contrast, the economy recovered quickly and median income increased rapidly between the second pair of years. From this follows that the poverty line for 2002 defined as 60 percent of the contemporary median will represent higher purchasing power than the poverty line for the two other years. In some of the computations we will consider this by updating the poverty line for 1990 by the Consumer Price Index, thus working with a poverty line that represents constant purchasing power.

\footnotetext{
${ }^{4}$ One example is older siblings, while studying, still living with the parents. In this situation, needs are underestimated and there is a risk that we classify a household and the person under 18 incorrectly as non-poor. Another example is units we classify as single parent units, which in reality can include another adult person with income of substantial size. In such a case there is the risk that we incorrectly classify the child as poor.
} 


\section{Describing child poverty at the neighbourhood level}

In this section we describe results on child poverty rates at the neighbourhood level in Sweden's metropolitan areas. While there are earlier writings on child poverty at the national level as well as at the municipality level, this is the first time information on child poverty rates at the level of the neighbourhood as defined here are reported. ${ }^{5}$ A first view is obtained in Figure 1 showing the distribution of neighbourhoods by child poverty rates in 1990, 1996 and 2002. Most neighbourhoods have child poverty rates lower than 20 percent, but there are also a few with much higher rates. The number of neighbourhoods with high child poverty rates is higher at the end of the period than at the beginning.

/Table 2 about here/

Child poverty has tended to become spatially more concentrated during the period under study. This is shown in Table 2 where we first rank neighbourhoods by number of poor children and then cumulate neighbourhoods and then report the cumulated percentage of all neighbourhoods. For example, we report that in 1990 half of all poor children lived in 20 percent of all neighbourhoods. The corresponding proportion of all neighbourhoods in 2002 had been reduced to 15 percent. In 2002, 90 percent of all poor children lived in 62 percent of all neighbourhoods.

/Figure 1 about here/

For some purposes it can be useful to classify neighbourhoods into a small number of categories based on their child poverty rates. How many to work with and where to put the dividing lines between such categories is arbitrary. Following practice in several US studies on poverty at the neighbourhood level (see for example Jargowsky, 1996), we define a neighbourhood with a child poverty rate of at least 40 percent as a "poor neighbourhood". Note that our definition of poverty at the household level is not comparable with the definition used in the United States. The official poverty line for the United States, when related to median income, is relatively close to 40 percent, not 60 percent which is the poverty line for

\footnotetext{
${ }^{5}$ For the entire country of Sweden see Ministry of Social Affairs (2004) and Gustafsson et al (2007). For estimates on poverty at the municipality level based on a somewhat different definition of poverty, see Save the Children Sweden (2008).
} 
Sweden. From this it follows that when compared to mainstream society for each country, we do not claim that the poor neighbourhoods in Sweden's metropolitan areas have a living standard that is as low as their counterparts in the United States.

In our data for 1990 there are 12 neighbourhoods with a proportion of poor children large enough to be qualified for the label "poor neighbourhood". The number had increased to 39 in 2002, thus an increase of 325 percent. The data shows that while there was only one neighbourhood with a child poverty rate over 50 percent in 1990, the number had increased to 19 in 2002. In an Appendix, available form authors on request, we list the 20 neighbourhoods with the highest and lowest child poverty rates, respectively, in 2002 and report some key variables. In 2002 Södra Rosengård, in the Malmö region had the highest child poverty rate, 78 percent (up from 46 percent in 1990), followed by Fittja in the Stockholm region (67 percent in 2002, up from 53 percent in 1990) and Norra Biskopsgården in the Gothenburg region (62 percent in 2002). When defining neighbourhoods with a poverty rate of higher than 20 percent, but lower than 40 percent, as “almost poor”, there were 109 such neighbourhoods in 1990, 164 in 1996 and the number had decreased in 2002 to 91 neighbourhoods.

\section{/Table 3 about here/}

While our results indicate a remarkably rapid increase in the number of poor neighbourhoods, and child poverty becoming spatially more concentrated, one should not forget that most poor children in the three metropolitan areas do not live in poor neighbourhoods. Table 3 shows that out of 120000 children classified as poor in 2002, a minority- less than $1 / 3$ of the children (37 000) - lived in the poor neighbourhoods, i.e., neighbourhoods with more than 40 percent poor children. True this is an increase from about one out of ten in 1990, yet the numerous neighbourhoods with low poverty rates contributed with the majority of poor children. Nevertheless we should keep in mind that the number of children living in poor neighbourhoods has increased from about 3 percent of all children in 1990 to 10 percent in 2002.

/Figure 2 about here/ 
Comparing child poverty rates in particular neighbourhoods over time, considerable mobility is observed. This becomes visible in Figure 2 where we have plotted child poverty rates in 1990 and in 2002 for each neighbourhood. It becomes clear that there has been rather large mobility among neighbourhoods that in 1990 were classified as almost poor; a relatively large fraction have become poor, others have experienced substantial drops in child poverty rates, while for a third category changes across year are small. The child poverty rate in 1990 is a reasonably good, though far from perfect predictor of the child poverty rate in 2002. The figure also shows that among initially poor neighbourhoods, a reduction in the child poverty rate was unusual.

\section{Ethnicity and child poverty}

Although immigration to Sweden by persons not citizens of the EU or Norway is restricted, many persons born in low- and middle-income countries in recent decades have entered as political refugees, through relatives or for related reasons. Many with roots in distant countries with low or medium-high GDP, differ by language, name and skin colour from the native population. Due to such reasons, many experience great difficulty finding a job. As a consequence of little or no labour market attachment, fewer visible immigrants are entitled to social insurance benefits compared with natives. For these reasons the income situation for immigrants is often worse than for the majority population. In contrast, many non-visible immigrants from rich countries do not face problems finding jobs similar to those of the majority.

A disproportionally large proportion of immigrants reside in the metropolitan areas under study in this paper. To study the relation between ethnicity and child poverty at the neighbourhood level, we have used one of several possible classifications. This classification is based on the rate between the number of visible foreign-born (of all ages) and the number of native-born (of all ages). For each of the three large city regions, the average rate of visible foreign-born to native born is computed and put equal to 1.0, and for each neighbourhood the corresponding ratio is computed. ${ }^{6}$ In this definition the number of non-visible foreign-born

\footnotetext{
${ }^{6}$ See Biterman and Franzén (2007) for the exact definition. It is to some extent arbitrary where the dividing line between visible foreign-born and other foreign-born should be put. Here people born in, e.g., Hungary, Russia, Rumania, Finland, Norway, Germany and the United States are considered to be non-visible foreign-born. This
} 
persons in a particular neighbourhood does not affect the ethnic classification of a neighbourhood. Based on the value for this variable, the neighbourhood is classified into one out of eight different categories. There are three categories of neighbourhoods with varying degrees of homogenous native-born population (values less than $0.25,0.25-0.49,0.50-$ 0.79 ), two categories of integrated neighbourhoods (values $0.80-1.24,1.25-1.99$ ) and three categories with a concentration of visible foreign-born $(2.0-3.99,4.00-9.99,10$ and higher).

We cross this classification of clusters of neighbourhoods with the classification of neighbourhoods by poor, almost-poor and non-poor, and show the results for each year under study in Figure 3. A strikingly clear pattern is observed. Neighbourhoods with a predominant majority population have low child poverty rates and neighbourhoods with a large fraction of visible minorities are without exception classified as almost-poor or poor neighbourhoods. In the category with the highest fraction of visible minorities, all neighbourhoods are classified as poor in 1996 as well as in 2002.

/Figure 3 about here /

Up to now we have worked with a poverty line that moves along with median income across the years for all persons in Sweden. The median in 2002 is considerably higher than that observed in 1990, and the purchasing power of the poverty line used up to now has thus increased. Will we show a similar picture of child poverty at the neighbourhood level if we keep the purchasing power of the poverty line from the base year? The answer to this question is found in Figure 4 where we show poverty rates computed using various assumptions for clusters of neighbourhoods with different ethnic compositions in 1990 and in 2002. Here we see that poverty rates in clusters with the highest concentration of majority population are the lowest, and actually decreased across the years. Turning to clusters with a large fraction of visible minorities, there are not only larger proportions of children under the contemporary poverty line in 2002 compared to 1990, but actually a larger proportion under a poverty line representing the same purchasing power as the poverty line of 1990.

is in contrast to persons born in, e.g., Yugoslavia (and its successor countries), Bulgaria, Greece, Spain and Italy who together with people from Asia, Africa and Latin America, are considered visible foreign-born. 
Figure 4 also show the proportion of children falling under a poverty line set to 40 percent of the median in 1990 and 2002, that is, the very poor. We see that actually around one in ten children living in neighbourhoods with a large fraction of visible minorities were very poor in 1990, and that in 2002 the proportion had more than doubled in the cluster with the highest fraction of visible minorities. Poverty has thus become more severe in the neighbourhoods with high concentrations of visible minorities.

/Figure 4 about here/

Parents in neighbourhoods with large fractions of visible minorities differ from those in ethnic homogenous neighbourhoods in many respects that in turn affect the child poverty rate. Figure 5 shows that their education level is lower than in neighbourhoods dominated by the majority. Comparing curves for various years shows improvement in parent education level in all clusters. Most visible is the drop in the fraction 'parents having elementary education or less' in the clusters with a high fraction of visible minorities. Figure 6 shows the expected pattern of parents' labour market attachment being highest in neighbourhoods dominated by the majority, and lowest in neighbourhoods with a large fraction of visible minorities. The large macroeconomic downturn from 1990 to 1996 is clearly visible in all clusters. However, the recovery from 1996 to 2002 was different across clusters. In clusters with a dominating majority population, actually a higher proportion of parents have a strong labour market attachment in 2002 than in 1990, while the contrary is the case in clusters with a large fraction of visible minorities. Another interesting point is that the recovery seems to have affected the fraction of parents having no work income, very little, or not at all.

/Figure 5 about here/

/Figure 6 about here/

In order to better understand what determines neighbourhood child poverty rates (expecting them to be strongly linked to parent's degree of labour mark attachment), we have estimated a regression model using a small number of explanatory variables for each of the years under study. Explanatory variables include continuous variables expressing parent's degree of 
labour market attachments, parent's education, demographic characteristics and proportion of children with parents born in non-rich or rich countries, respectively. We expect that once we control for labour market attachment and education, status as immigrant from middle- and low-income country has little independent effect on the neighbourhood child rate. In the specification there are also dummy variables indicating in which metropolitan region the neighbourhood is located.

/Table 4 about here/

The estimates reported in Table 4 show that in our specification a surprisingly high proportion of the variation in child poverty rates can be explained. The $\mathrm{R}^{2}$ is 0.87 in 1990 and as high as 0.97 in 2002. Many coefficients are of similar magnitude for all years, with an increase in the negative coefficients for education as the main exception. Generally it is the difference between having at least a secondary education or not that matters for the neighbourhood child poverty rate, while it makes little difference if the parent's education is secondary or higher. Most importantly, the negative coefficients for strong labour market attachment of parents are high. In contrast, the coefficients indicating fraction of children with parents born in non'-rich countries are small, although statistically significant on conventional levels. The high child poverty rates we have reported for neighbourhoods with a large fraction of visible minorities are thus to a large degree due to the parents' weak labour market attachment and low education, not their immigrant status per se. Although these results are very much expected, they nevertheless merit being related. ${ }^{7}$

\section{Conclusions}

This paper has explored a rich database on neighbourhoods in three metropolitan regions of Sweden. We have focused on child poverty as defined by information on disposable income for all families with children living in 574 neighbourhoods for 1990, 1996 and 2002. During this period the immigrant population grew, particularly for people having roots in middle- and

\footnotetext{
${ }^{7}$ These results parallel those that Urban (2009) reports on adult effects of growing up in various neighbourhoods in Stockholm. She concludes that economic characteristics of the neighbourhoods have larger impact than ethnic characteristics.
} 
low-income countries, and residential segregation became a hot topic in Swedish policy debate and policymaking.

We show clear indications of increased residential segregation when studying child poverty rates. The number of neighbourhoods with child poverty rates lower than 10 percent was larger in 2002 than in 1990. Starting from a low base, the number of neighbourhoods with child poverty rates of at least 40 percent was many times larger in 2002 than in 1990. However, although there is a clear tendency for child poverty to become more spatially concentrated, in 2002 most poor children in the three metropolitan areas actually live outside poor neighbourhoods.

This study has shown that there is a very strong relation between ethnic composition and poverty status at the neighbourhood level. All neighbourhoods with high fractions of visible minorities are poor neighbourhoods in 1996 as well as in 2002. Children living in neighbourhoods with high fractions of visible immigrants have a larger fraction of parents with little or no labour market attachment, and the parents have on average shorter educations than parents living in neighbourhoods dominated by the majority population. Such circumstances, not foreign background per se, form the root of the high child poverty rates in neighbourhoods with fractions of visible immigrants. This conclusion was drawn from estimates of regression models in which child poverty rates at the neighbourhood level were regressed to a small number of explanatory variables. 


\section{References}

Anderson, R. (2006) “'Breaking Segregation' - Rhetorical Construction or Effective Policy? The Case of the Metropolitan Development Initiative in Sweden”, Urban Studies, 43, no 4, $787-799$.

Atkinson, A., Cantillon, B., Marlier, E. and Nolan, B. (2002) Social Indicators. The EU and Social Inclusion, Oxford: Oxford University Press.

Biterman, D. and Franzén, E. (2007) Residential segregation (Chapter 6) in (Social report 2006. The National Report on Social Conditions in Sweden) International Journal of Social Welfare, Vol. 16, July Supplement 2007

Biterman, D. Gustafsson, B. and Österberg, T (2008) Economic and Ethnic Polarisation among Children in Sweden's Three Metropolitan Areas”, Schmollers Jahrbuch. Journal of Applied Social Science Studies, 128, 121 - 152.

Gustafsson, B., Zaidi, A. and Franzén, E. (2007) ”Financial Poverty”, International Journal of Social Welfare, 16, Supplement 1 (Social Report 2006. The National Report on Social Conditions in Sweden) 67 - 90..

Jargowsky, P.A. (1996) Poverty and Place. Ghettos, Barrios and the American City, New York: Russell Sage.

Save the Children Sweden (2008) Barnfattigdom i Sverige 2007. Årsrapport. Stockholm

Ministry of Finance (1998). Utveckling och rättvisa - en politik för storstaden på 2000-talet [Development and justice: A policy for metropolitan areas in the 21st century]. Prop 1997/98:165

Ministry of Social Affairs (2004) Ekonomiskt utsatta barn, Stockholm Ds 2004:41.

OECD (2008) Growing Unequal? Income Distribution and Poverty in OECD Countries, Paris.

Urban, S. (2009) 'Is the Neighbourhood Effect an Economic or an Immigrant Issue? A Study of the Importance of the Childhood Neighbourhood for Future Integration into the Labour Market”, Urban Studies, 46 (3), 583 - 603. 
Table 1

Definition of the three large city regions, number of neighbourhoods, population size and country of origin composition.

\begin{tabular}{|c|c|c|c|}
\hline Region & Stockholm & Göteborg & Malmö \\
\hline Municipalities & \begin{tabular}{|lr} 
Stockholm, & Solna, \\
Sundbyberg, & \\
Danderyd, & \\
Ekerö, & \\
Järfälla, & Lidingö, \\
Sigtuna, & Sollentuna, \\
Täby, Upplands-Bro, & Uärolar, \\
Upplands & Väsby, \\
Vallentuna, & Österåker, \\
Botkyrka, & Haninge, \\
Huddinge, & Nacka, \\
Salem, & Turesö, \\
Värmdö, & Norrtälje, \\
Nynäshamn & and \\
Södertälje &
\end{tabular} & $\begin{array}{l}\text { Göteborg, Kungälv, } \\
\text { Ale, Lerum, Partille, } \\
\text { Härryda, Mölndal and } \\
\text { Kungsbacka }\end{array}$ & 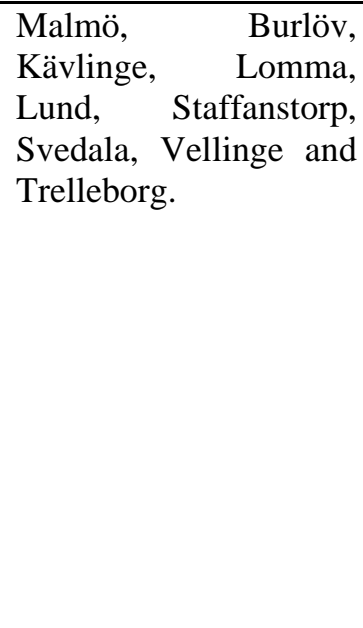 \\
\hline $\begin{array}{l}\text { Number } \\
\text { neighbourhoods }\end{array}$ & 337 & 205 & 154 \\
\hline $\begin{array}{l}\text { Urban neighbourhoods } \\
\text { with a population } \\
\text { larger than } 500 \text { persons }\end{array}$ & 271 & 138 & 92 \\
\hline $\begin{array}{l}\text { Total population as of } \\
2002\end{array}$ & 1083600 & 769900 & 528300 \\
\hline $\begin{array}{l}\text { Foreign-born } \\
\text { population as of } 2002\end{array}$ & 324400 & 116400 & 90700 \\
\hline $\begin{array}{l}\text { Foreign-born } \\
\text { population } 2002 \text { as } \\
\text { percent of the total } \\
\text { population in the } \\
\text { region }\end{array}$ & 18 & 15 & 17 \\
\hline
\end{tabular}

\section{Table 2}

\section{Concentration of neighbourhood child poverty.}

The proportion of all neighbourhoods in which given proportion of poor children live 1990, 1996 and 2002

\begin{tabular}{||l|l|l|l||}
\hline & $\mathbf{1 9 9 0}$ & $\mathbf{1 9 9 6}$ & $\mathbf{2 0 0 2}$ \\
\hline $\mathbf{5 0}$ & 20 & 17 & 15 \\
\hline $\mathbf{7 5}$ & 43 & 40 & 38 \\
\hline $\mathbf{9 0}$ & 66 & 63 & 62 \\
\hline
\end{tabular}

Note: A child is defined if the disposable equivalent income in the household is less than 60 percent of contemporary disposable median income. 
Table 3

Number of children that are poor 1990 and 2002 in neighbourhoods that are classified as not poor, almost poor and poor.

\begin{tabular}{|c|c|c|c|c|}
\hline & $\begin{array}{r}0-19,9 \text { poor in } \\
\text { neighbourhood }\end{array}$ & $\begin{array}{l}20-39,9 \text { poor in } \\
\text { neighbourhood }\end{array}$ & $\begin{array}{r}>40 \text { poor in } \\
\text { neighbourhood }\end{array}$ & Total \\
\hline \multicolumn{5}{|l|}{$\underline{1990}$} \\
\hline Number of poor children & 54669 & 26487 & 9169 & 90325 \\
\hline Number of children & 460867 & 101887 & 20265 & 583019 \\
\hline \multicolumn{5}{|l|}{$\underline{1996}$} \\
\hline Number of poor children & 54457 & 43158 & 32411 & 130026 \\
\hline Number of children & 422120 & 161568 & 57847 & 583688 \\
\hline \multicolumn{5}{|l|}{$\underline{2002}$} \\
\hline Number of poor children & 55757 & 27729 & 37383 & 120869 \\
\hline Number of children & 499791 & 104979 & 68830 & 673600 \\
\hline
\end{tabular}

Note: A child is defined if the disposable equivalent income in the household is less than 60 percent of contemporary disposable median income. 
Table 4

Determinants of child poverty rates at the neighbourhood level. Ordinary least squares regression.

\begin{tabular}{|c|c|c|c|c|c|c|c|c|c|}
\hline \multirow[b]{3}{*}{ (Constant) } & \multicolumn{3}{|l|}{1990} & \multicolumn{2}{|l|}{1996} & \multicolumn{3}{|c|}{2002} & \multirow[b]{2}{*}{ Sig. } \\
\hline & $\mathbf{B}$ & $\begin{array}{l}\text { Std. } \\
\text { Error }\end{array}$ & Sig. & $\mathbf{B}$ & $\begin{array}{l}\text { Std. } \\
\text { Error }\end{array}$ & Sig. & $\mathbf{B}$ & $\begin{array}{l}\text { Std. } \\
\text { Error }\end{array}$ & \\
\hline & 0,492 & 0,104 & $<, 0001$ & 0,492 & 0,093 & $<, 0001$ & 1,167 & 0,099 & $<, 0001$ \\
\hline Mean mother's age when child is born & 0,012 & 0,003 & $<, 0001$ & 0,013 & 0,003 & $<, 0001$ & $-0,004$ & 0,002 & 0,088 \\
\hline Mean age of child & 0,006 & 0,002 & 0,001 & 0,009 & 0,002 & $<, 0001$ & 0,000 & 0,002 & 0,874 \\
\hline \multicolumn{10}{|l|}{ Reference: fraction of children with Swedish-born parents } \\
\hline Fraction of children with parents born in non-rich countries & 0,074 & 0,028 & 0,009 & 0,099 & 0,026 & 0,000 & 0,099 & 0,017 & $<, 0001$ \\
\hline Fraction of children with parents born in rich countries & $-0,040$ & 0,040 & 0,310 & $-0,122$ & 0,050 & 0,015 & $-0,109$ & 0,052 & 0,037 \\
\hline \multicolumn{10}{|l|}{$\begin{array}{l}\text { Reference: fraction of household where both parents have } \\
\text { compulsory education }\end{array}$} \\
\hline Fraction with one parent compulsory education & $-0,103$ & 0,062 & 0,097 & $-0,108$ & 0,070 & 0,122 & $-0,149$ & 0,087 & 0,088 \\
\hline Fraction with one or both parents secondary education & $-0,196$ & 0,055 & 0,000 & $-0,242$ & 0,056 & $<, 0001$ & $-0,482$ & 0,067 & $<, 0001$ \\
\hline Fraction with at least one parent short university education & $-0,224$ & 0,053 & $<, 0001$ & $-0,213$ & 0,057 & 0,000 & $-0,347$ & 0,070 & $<, 0001$ \\
\hline Fraction with one parent long university education & $-0,260$ & 0,056 & $<, 0001$ & $-0,303$ & 0,063 & $<, 0001$ & $-0,327$ & 0,072 & $<, 0001$ \\
\hline Fraction with both parents long university education & $-0,213$ & 0,057 & 0,000 & $-0,294$ & 0,065 & $<, 0001$ & $-0,371$ & 0,073 & $<, 0001$ \\
\hline Larger- Stockholm & 0,032 & 0,004 & $<, 0001$ & 0,022 & 0,004 & $<, 0001$ & 0,020 & 0,004 & $<, 0001$ \\
\hline Larger - Gothenburg & 0,008 & 0,004 & 0,031 & 0,001 & 0,004 & 0,775 & 0,001 & 0,003 & 0,858 \\
\hline Fraction single parents & $-0,245$ & 0,018 & $<, 0001$ & $-0,401$ & 0,018 & $<, 0001$ & $-0,309$ & 0,015 & $<, 0001$ \\
\hline \multicolumn{10}{|l|}{ Reference none of the parents have working income } \\
\hline Both parents strong labour market attachment & $-0,774$ & 0,063 & $<, 0001$ & $-0,749$ & 0,046 & $<, 0001$ & $-0,722$ & 0,036 & $<, 0001$ \\
\hline One parent strong labour market attachment & $-0,455$ & 0,064 & $<, 0001$ & $-0,498$ & 0,048 & $<, 0001$ & $-0,388$ & 0,034 & $<, 0001$ \\
\hline Both parents low labour market attachment & 0,094 & 0,075 & 0,209 & 0,017 & 0,052 & 0,748 & $-0,071$ & 0,053 & 0,180 \\
\hline Adjusted $\mathbf{R}^{2}$ & 0,874 & & & 0,946 & & & 0,965 & & \\
\hline
\end{tabular}


Figure 1. Distribution of percentage poor in neighbourhoods $(n=574) 1990$ and 2002

Figure 1. Distribution of percentage poor in neighbourhoods (n=574) 1990 and 2002

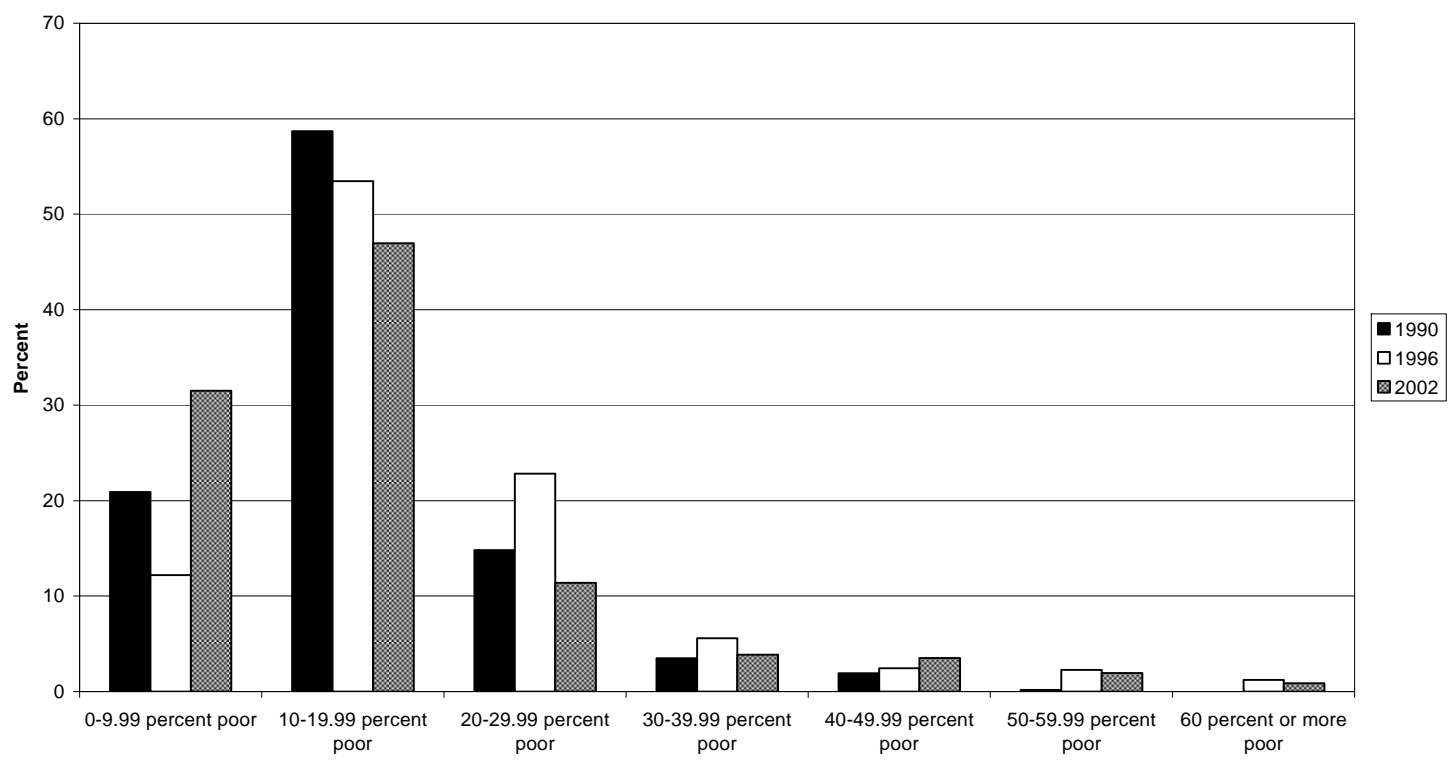


Figure 2.

Child poverty rates at neighbourhood level 1990 and 2002.

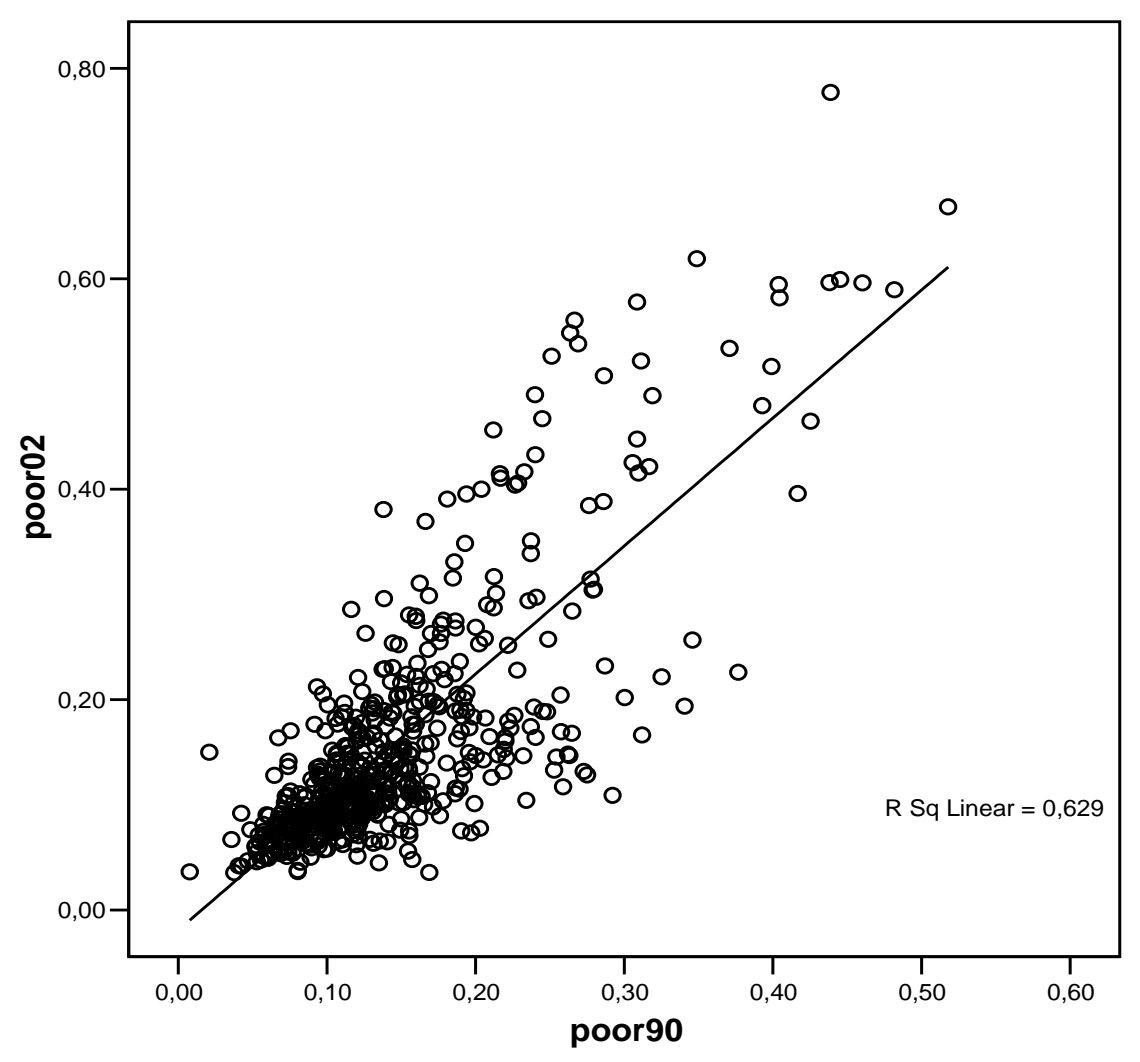


Figure 3

Neighbourhoods after classification of ethnicity and child poverty rates, 1990, 1996 and 2002 Percentage of neighbourhoods belonging to a certain povertygroup within each group of ethnic classification 1990

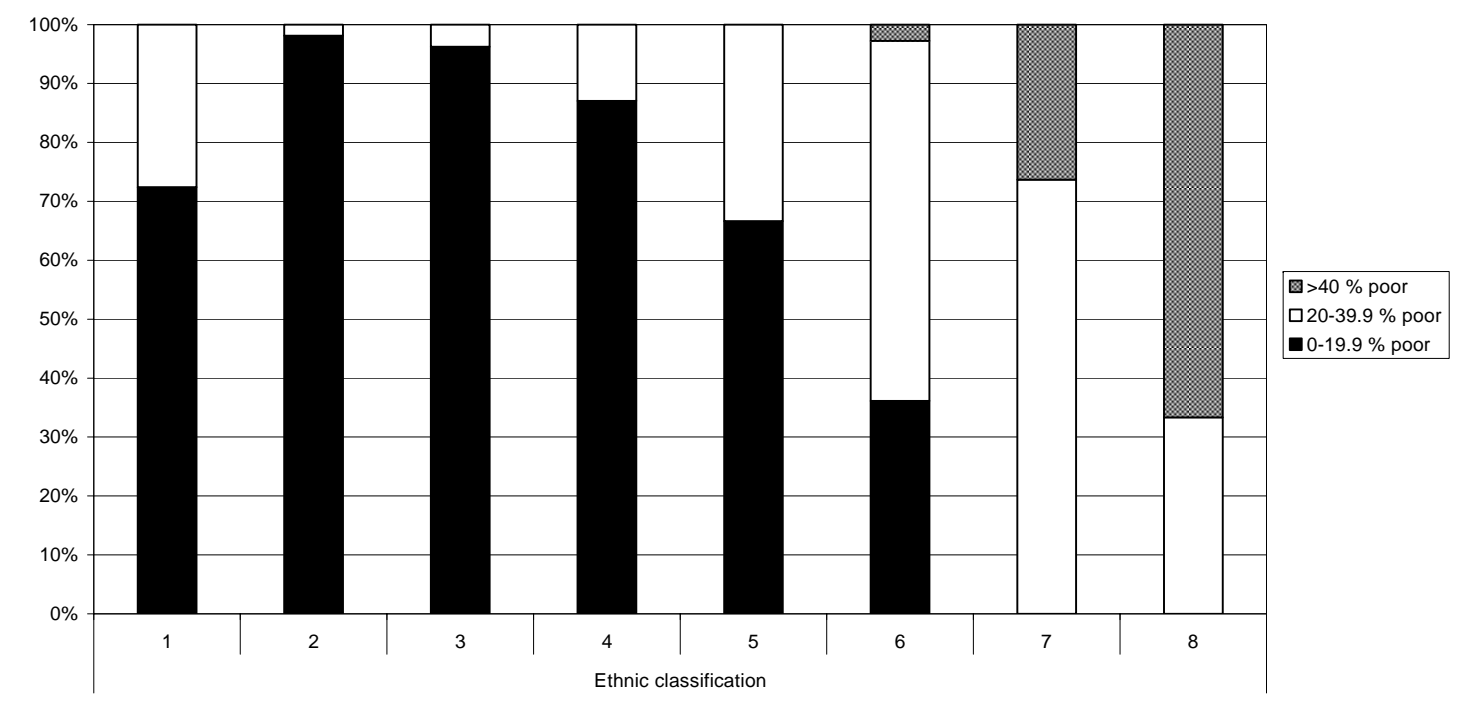


Percentage of neighbourhoods belonging to a certain povertygroup within each group of ethnic classification

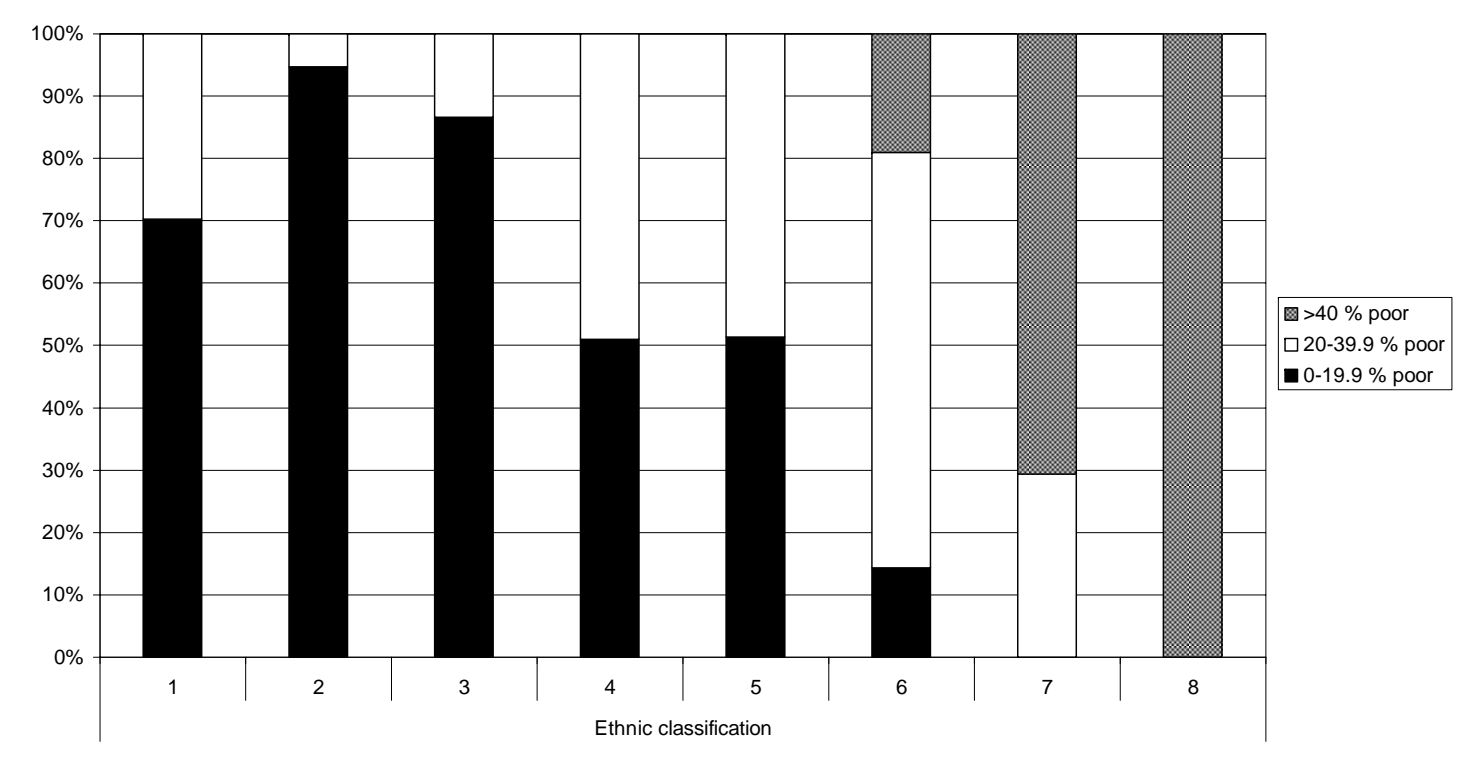


Percentage of neighbourhoods belonging to a certain povertygroup within each group of ethnic classification

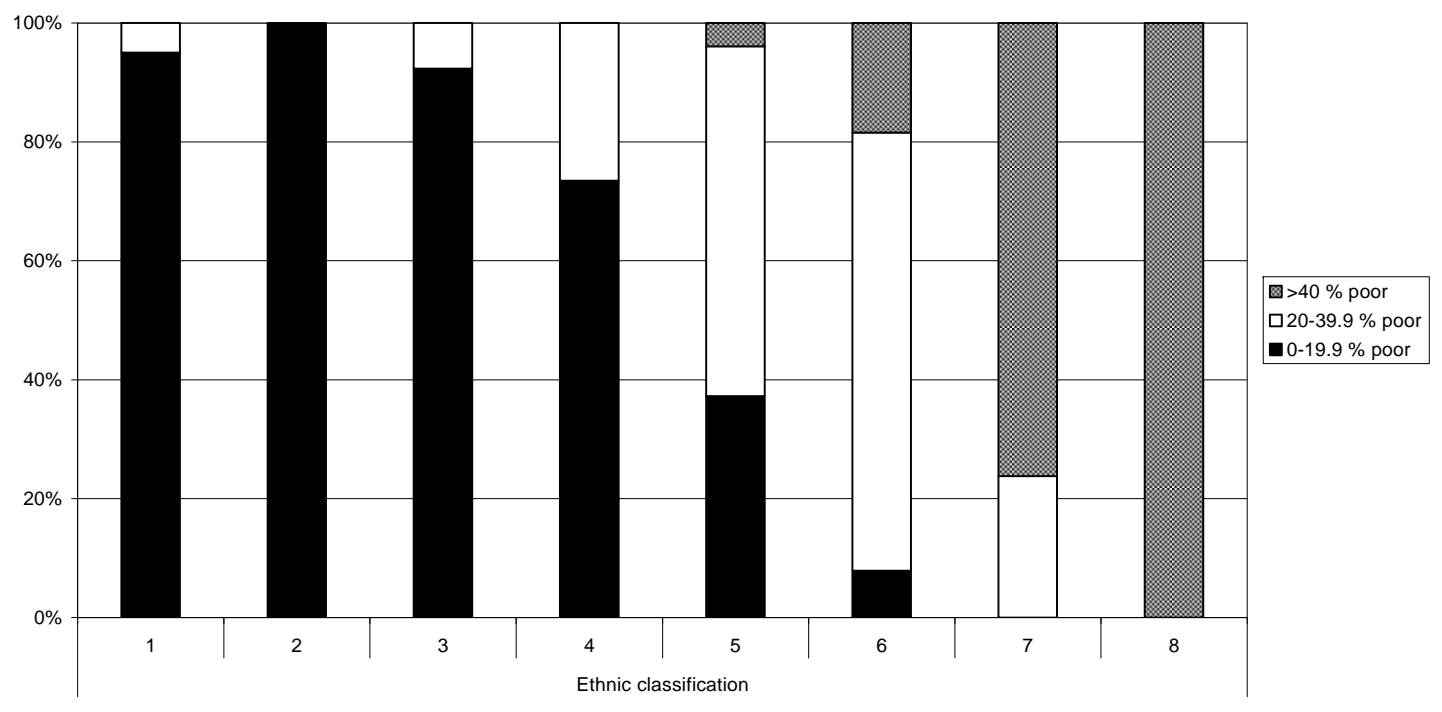


Figure 4

Poverty rates in clusters of neighbourhoods defined by ethnicity

Percentage poor in neighbourhoods by ethnic classification 1990 and 2002

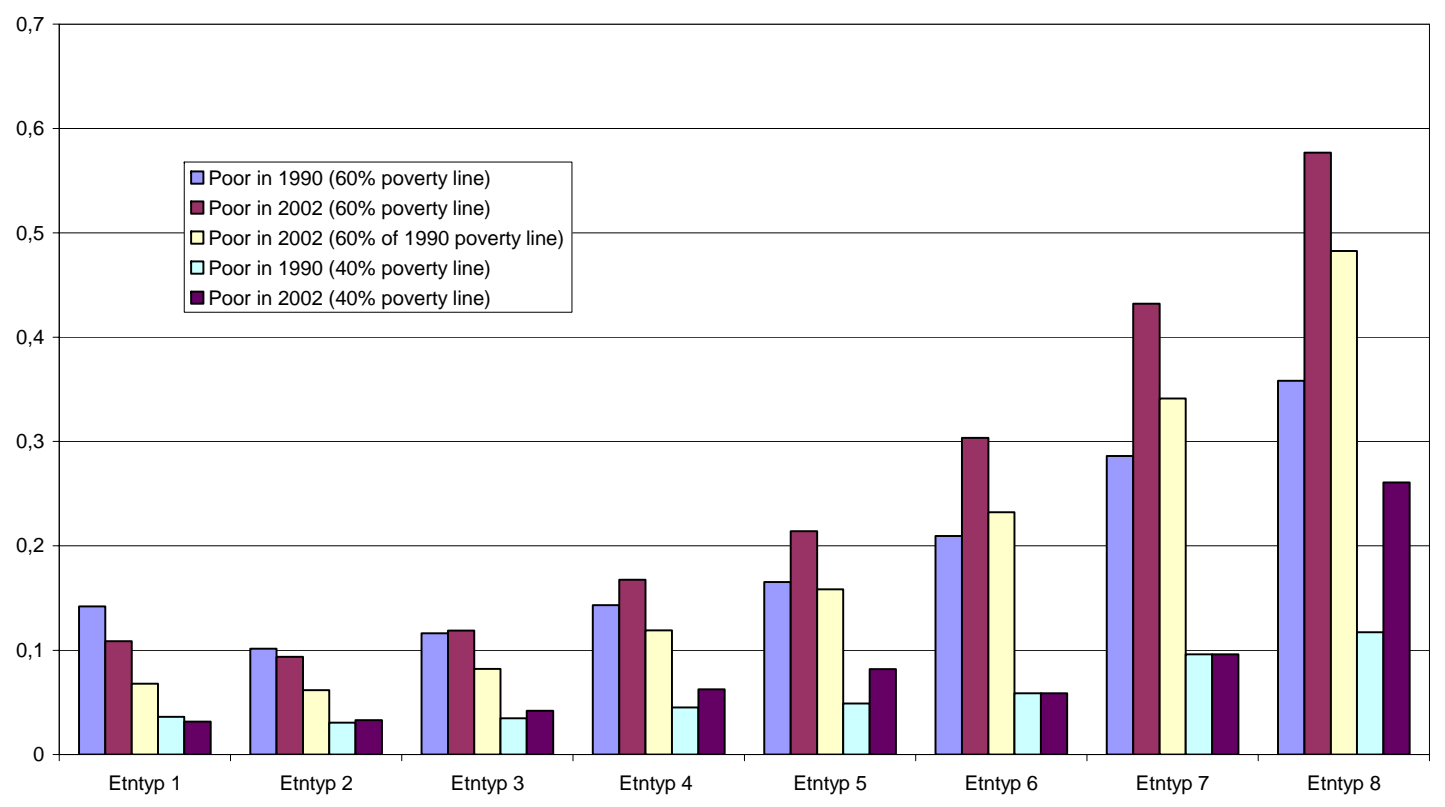




\section{Figure 5}

Parental education in clusters of regions by ethnic classification of neighbourhood 1990, 1996 and 2002.

Share with highest and lowest educational category by ethnic classification of neighbourhood

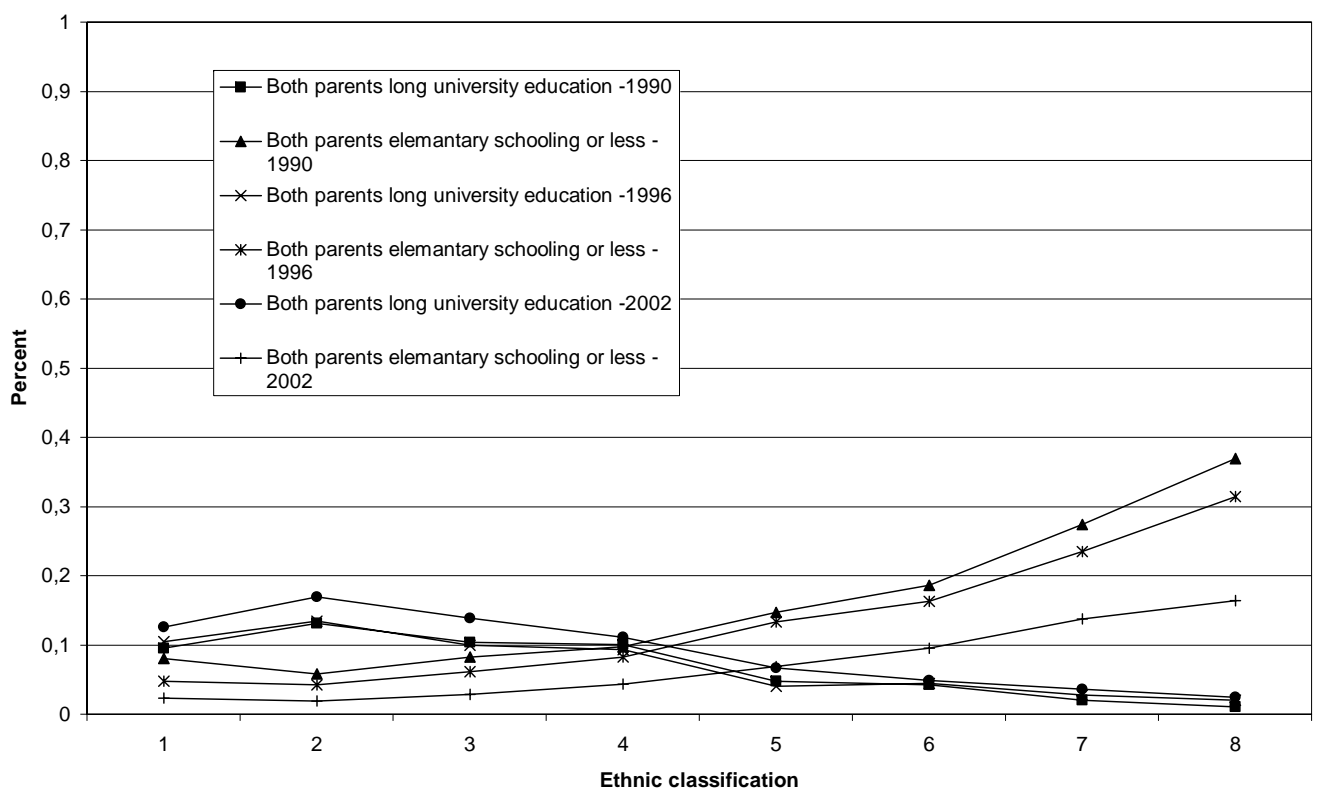


Figure 6 Parental labour market attachment in clusters by ethnic classification of neighbourhood 1990, 1996 and 2002.

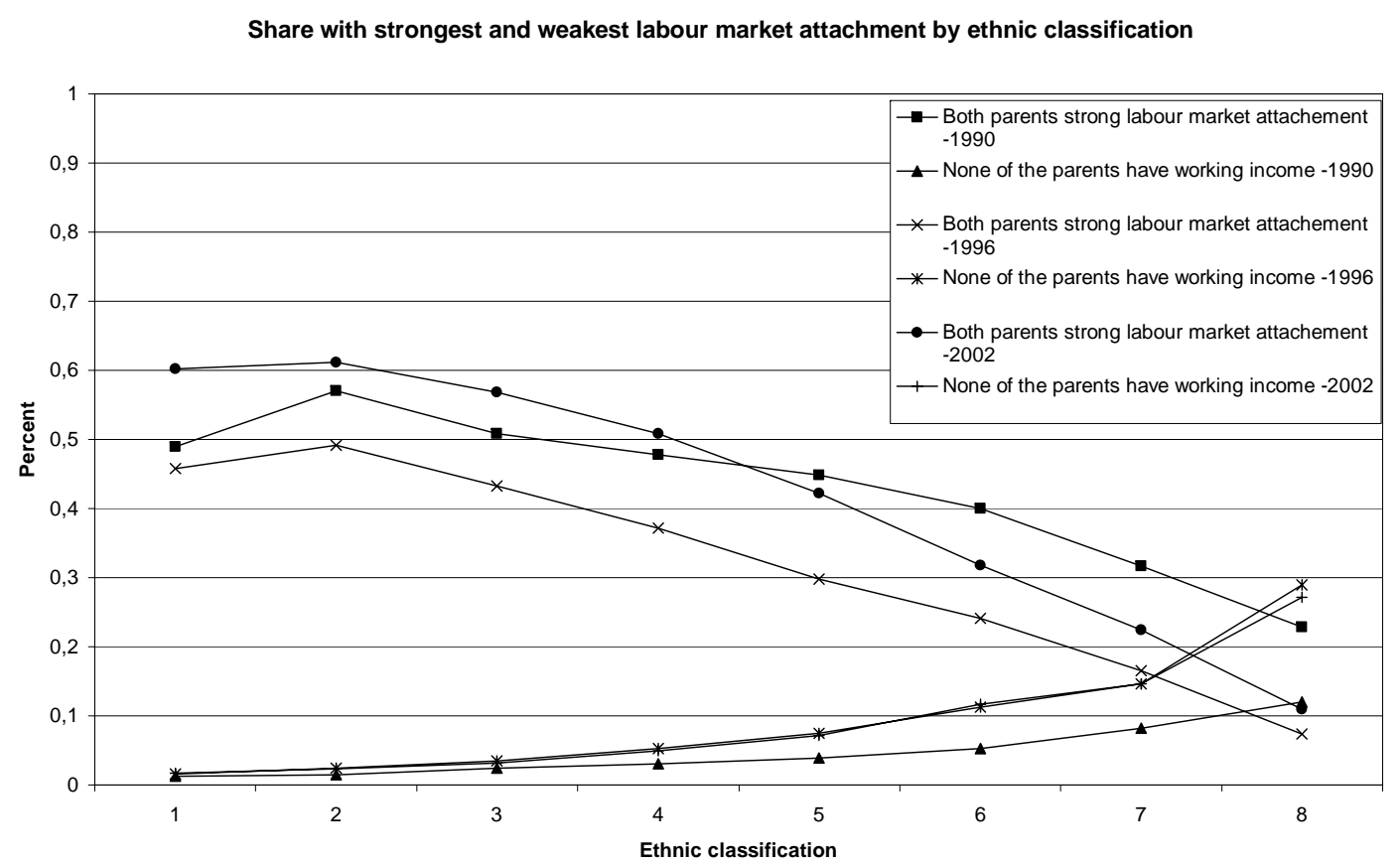

